\title{
Understanding the Patient Experience of Hunger and Improved Quality of Life with Setmelanotide Treatment in POMC and LEPR Deficiencies
}

\author{
Martin Wabitsch • Sheri Fehnel • Usha G. Mallya • Martina Sluga-O'Callaghan • \\ David Richardson · Mark Price · Peter Kühnen (D)
}

Received: December 20, 2021 / Accepted: January 26, 2022 / Published online: February 22, 2022

(C) The Author(s) 2022

\begin{abstract}
Introduction: In patients with pro-opiomelanocortin (POMC) or leptin receptor (LEPR) deficiency, managing obesity and hyperphagia can be burdensome for patients and caretakers. The impacts on health-related quality of life are under-recognized and are not well characterized.
\end{abstract}

Supplementary Information The online version contains supplementary material available at https:// doi.org/10.1007/s12325-022-02059-8.

S. Fehnel · M. Sluga-O'Callaghan - D. Richardson · M. Price

RTI Health Solutions, Research Triangle Park, NC, USA

U. G. Mallya

Rhythm Pharmaceuticals, Inc, Boston, MA, USA

P. Kühnen $(\varangle)$

Institute for Experimental Pediatric Endocrinology, Charité-Universitätsmedizin Berlin, Corporate

Member of Freie Universität Berlin, Humboldt-

Universität Zu Berlin, and Berlin Institute of Health,

Augustenburger Platz 1, 13353 Berlin, Germany

e-mail: peter.kuehnen@charite.de

M. Wabitsch $(\bowtie)$

Division of Paediatric Endocrinology and Diabetes,

Centre for Hormonal Disorders in Children and

Adolescents, Department of Paediatrics and

Adolescent Medicine, Ulm University Hospital,

Eythstraße 24, 89075 Ulm, Germany

e-mail: martin.wabitsch@uniklinik-ulm.de
Methods: We conducted in-depth qualitative interviews in patients with POMC $(n=3)$ and LEPR $(n=2)$ deficiencies participating in an ongoing open-label extension of phase 3 clinical trials with the melanocortin receptor 4 agonist setmelanotide to describe the patient experience of hyperphagia and characterize changes following treatment with setmelanotide.

Results: Prior to setmelanotide treatment, all five patients described abnormal sensations of hunger with none indicating feeling satiated after meals and also reported that the burden of hyperphagia impacted their families, emotions, and work and/or school functioning. Following setmelanotide treatment, all five patients reported consistent reductions in hunger and weight, decreased eating, and feeling satiated after meals in addition to substantial improvements in each area of functioning they had previously reported. All five patients indicated they were very satisfied with the impact of setmelanotide on their quality of life and would be upset if treatment was discontinued.

Conclusions: In patients with POMC or LEPR deficiency, hyperphagia and the inability to feel satiety negatively impacted quality of life. By reducing hunger and improving satiety, setmelanotide facilitated important changes in the lives of these patients. This qualitative research study suggests that the impact of setmelanotide goes beyond favorable clinical changes (e.g., weight and hunger) to also include quality of 
life improvements that are highly meaningful to patients.

Keywords: Disease Burden; Hyperphagia; Leptin Receptor; Melanocortin Receptor; ProOpiomelanocortin; Rare Genetic Diseases of Obesity

\section{Key Summary Points}

Pro-opiomelanocortin (POMC) and leptin receptor (LEPR) deficiencies are rare genetic diseases of obesity that are associated with insatiable hunger, which places tremendous burdens on both patients and caretakers; these burdens are not well characterized.

We conducted in-depth interviews in a cohort of patients with POMC and LEPR deficiencies who received treatment with setmelanotide and found a decrease in the daily burdens of insatiable hunger that had meaningful impacts on the patients' health-related quality of life.

Results from this qualitative study are consistent with those reported in phase 3 trials of setmelanotide and suggest that the impacts of setmelanotide treatment also include patients' health-related quality of life improvements.

\section{INTRODUCTION}

Obesity is a multifactorial disease with detrimental impacts on long-term health, given its associations with increased mortality and morbidity, distress related to social stigma, and subsequent impact on health-related quality of life (HRQOL) [1-7]. Individuals classified as having severe obesity (body mass index $\geq 35 \mathrm{~kg} / \mathrm{m}^{2}$ ) and those with or without chronic comorbidities (e.g., diabetes mellitus, hypertension, and coronary heart disease) have reported decreased HRQOL associated with obesity [2, 5-7]. In adults and children, obesity is commonly related to psychological complications that can impact daily living such as anxiety, depression, and low self-esteem $[3,8,9]$.

Genetics can play a role in the development of obesity, as exemplified by rare genetic diseases of obesity [10-12]. Many of these diseases present with mutations in genes that function in the melanocortin receptor 4 (MC4R) pathway, a hypothalamic pathway regulating hunger and energy balance [11-13]. Deficiencies in key genes in the MC4R pathway, including proopiomelanocortin (POMC) and leptin receptor (LEPR), can disrupt MC4R signaling, which often results in insatiable hunger, known as hyperphagia, and early-onset severe obesity [11-13].

In two open-label phase 3 clinical trials (NCT02896192 and NCT03287960), the MC4R agonist setmelanotide demonstrated significant reductions in body weight and hunger scores, along with general improvements in cardiometabolic parameters [14]. Patients with obesity due to POMC $(n=9)$ or LEPR $(n=11)$ deficiency received setmelanotide treatment for 52 weeks (including 4 weeks of placebo); $80 \%$ of patients in the POMC trial and 45\% in the LEPR trial had at least $10 \%$ weight loss after approximately 1 year [14]. Additionally, $43 \%$ of patients in the POMC trial and $86 \%$ in the LEPR trial achieved at least $25 \%$ reduction in peak hunger score [14]. From the results of these clinical trials, setmelanotide was approved by the US Food and Drug Administration in November 2020 for the treatment of patients at least 6 years of age with POMC, LEPR, or proprotein convertase subtilisin/kexin type 1 deficiency [15].

While significant changes in weight and hunger were observed, the clinical trial data may not fully provide information on the potential impact of setmelanotide, especially the patient experience of hyperphagia and beneficial effects on HRQOL. In patients with POMC or LEPR deficiency, managing hyperphagia can be a daily struggle, placing extreme psychological burden on the patients, their family members, and their caretakers [16]. Because POMC and LEPR deficiencies are rare 
diseases, this burden and the impact on HRQOL are under-recognized and not well characterized in the literature [16].

Here, we conducted in-depth qualitative interviews with patients with POMC and LEPR deficiencies who participated in phase 3 clinical trials of setmelanotide and enrolled in the ongoing open-label extension of these trials (NCT03651765). This qualitative research was conducted as a substudy of this open-label extension in collaboration with two clinical sites in Germany; the primary objectives were to understand the hyperphagia and eating patterns among patients with POMC and LEPR deficiencies and characterize changes experienced by these patients following treatment with setmelanotide as they relate to HRQOL.

\section{METHODS}

Patients who were enrolled in phase 3 clinical trials of setmelanotide treatment for POMC or LEPR deficiencies at two clinical sites in Germany were eligible to undergo in-depth qualitative interviews conducted using (Zoom Video Communications, Inc.) from January 29 to February 16, 2021. Additional patient eligibility criteria included age 15 years or older, previous diagnosis of POMC or LEPR deficiencies, participation in the open-label extension study (NCT03651765), and informed consent (i.e., willingness and ability to participate in a 1-h, audio-recorded interview) being given. Patients were contacted via email to schedule the interviews. Interviews were conducted in German. Interviews followed a semistructured interview guide; while there was no separate pilot testing, the guide was modified following the first few interviews to improve flow (see Appendix A and Appendix B in the electronic supplementary material). During the interview, patients were asked to describe their experience of hunger, as well as the impacts of hunger on their lives prior to setmelanotide treatment. Subsequently, patients were also asked to describe changes in hunger, weight, and functioning after initiating setmelanotide treatment, including the perceived meaningfulness of the changes. Last, patients described their satisfaction with setmelanotide and how they would feel if they had to discontinue therapy. Each interview was audio recorded, transcribed, and translated into English for analysis. Conventional conceptual content analysis methods were used to analyze the translated transcripts. Given the small sample size and goals of the interviews, data saturation was not discussed.

In compliance with the International Council on Harmonisation for Good Clinical Practice, all patients provided informed consent for data to be presented in aggregate and anonymously. Given that POMC and LEPR deficiencies are rare genetic diseases, the qualitative data are presented here with limited identifying information to preserve patient confidentiality. Accordingly, we present categorical data focusing on three main topics: the patient experience of hunger prior to setmelanotide use, changes in hunger and hunger-related impacts noted by patients with setmelanotide treatment, and overall patient satisfaction with treatment. These three main research themes were identified in advance of the interviews.

This study was conducted in accordance with ethical principles founded in the Declaration of Helsinki. The institutional review board (IRB)/independent ethics committee (IEC) reviewed and approved all appropriate study documentation. Interview guides were reviewed by MW and PK and approved by the Ethics Commission Berlin (LAGeSo EK Berlin).

\section{RESULTS}

\section{Patient Characteristics}

In the open-label extension of the phase 3 setmelanotide clinical trials (NCT03651765), there were a total of 10 patients with POMC $(n=7)$ or LEPR $(n=3)$ deficiency enrolled at two clinical sites in Germany. This substudy cohort consisted of five of these patients with POMC $(n=3)$ or LEPR $(n=2)$ deficiency who met eligibility criteria and gave informed consent to participate in these interviews. The average age was 23.8 years (range, 15-33 years), and four of the five patients were male. One patient was hearing impaired, and the interview was 
facilitated by the mother, who responded to interview questions on behalf of the patient.

\section{Patient Experience Prior to Setmelanotide Treatment}

\section{Feelings of Hunger}

Patients were asked to describe their hunger before participating in their first clinical trial of setmelanotide, which was typically 3-4 years prior to the interview. Given the elapsed time since initiating treatment, it was difficult for some patients to remember details such as the magnitude of variations in their hunger; however, all five patients were able to characterize the general nature of their hunger. All five patients described abnormal sensations of hunger; two patients described the sensation as a strong psychological desire, much like addiction (Table 1 and Fig. 1). Despite clearly describing hyperphagia when relaying their experiences with hunger, none of the patients were familiar with the term.

While most patients described hunger as always or nearly always present, one patient with LEPR deficiency described extended periods with no hunger or desire for food. Another patient with POMC deficiency reported variations in hunger related to environment and activities, indicating that hunger was less noticeable while being out of the house and "distracted." Two patients indicated that the absence of hunger was relatively unusual and short lived, and one patient with POMC deficiency indicated they were never without a feeling of hunger before starting treatment. All five patients described strong feelings of hunger in relation to their preferred foods, which generally included sweets and highly processed carbohydrates.

Patients easily reported the nature of their hunger before starting treatment; however, two patients expressed difficulty in precisely recalling and rating the average intensity. When asked to score their average pretreatment hunger on a numerical rating scale ranging from 0 to 10 , all five patients reported scores ranging from 7 to 9 . Four patients scored their maximum hunger as a 10 on the scale, while the remaining patient with POMC deficiency had difficulty recalling maximum hunger and did not provide a score.

\section{Eating Habits}

The primary focus of the interview was on hunger experienced by patients; however, each described their eating habits. Common habits among patients were eating in secrecy, eating quickly, eating large amounts of food, and feeling a lack of control, particularly in relation to desired foods (Table 1). When asked if they felt full or satisfied after eating, no patients described a clear, unequivocal feeling of satiety (Fig. 1). Instead, patients either assumed they felt full, given they stopped eating at some point, or reported no recollection of feelings of fullness. When patients reported some level of satisfaction after eating, this feeling was generally short-lived.

\section{Impacts of Hyperphagia on HRQOL}

Beyond the impact of hyperphagia on weight, all five patients reported additional psychological, social, and health-related consequences impacting their HRQOL. Every patient reported negative emotions stemming from their inability to control their desire for food, including guilt, frustration, sadness, and even feelings of failure (Table 1). Additionally, when asked to share what bothered them the most about their hunger before starting treatment, patients commonly cited the emotional struggle with hunger and the inability to control the urge to eat.

Social and health-related consequences of hyperphagia influenced both family dynamics and work/school performance. While most of the patients in this cohort are now adults living independently, all five reported impacts on their families, particularly their mothers. Arguments and strains in these relationships often stemmed from the need for parents to monitor and limit food intake. One patient with LEPR deficiency reported a particularly traumatic experience of being removed from their childhood home at age 4; health care professionals believed the problem was due to the mother 
Table 1 Patient-reported experiences of hunger, eating habits, and impact of hyperphagia prior to clinical trials with setmelanotide

\begin{tabular}{|c|c|c|}
\hline Feelings of hunger & Eating habits & Impacts of hyperphagia \\
\hline $\begin{array}{l}\text { “It sometimes felt as if I were an animal } \\
\text { that was super hungry and could only } \\
\text { think about food, and when I wanted } \\
\text { to eat something, I searched until I } \\
\text { found it.” } \\
\text { Patient with POMC deficiency }\end{array}$ & $\begin{array}{l}\text { “When I would start eating something, } \\
\text { I'd eat the whole thing. No matter } \\
\text { what sort of package it was, or } \\
\text { whatever, I'd always eat the whole } \\
\text { thing. I also ate it at an enormous } \\
\text { tempo... It was really terrible.” } \\
\text { Patient with LEPR deficiency }\end{array}$ & $\begin{array}{l}\text { "I was a happy child, but the emotions, } \\
\text { particularly when it came to food, } \\
\text { were often, well, guilt feelings, huge } \\
\text { guilt feelings. Because you must hide } \\
\text { everything all the time. You lie, and } \\
\text { your mother notices it anyway. It was } \\
\text { always a huge feeling of guilt." } \\
\text { Patient with POMC deficiency }\end{array}$ \\
\hline $\begin{array}{l}\text { “What I recall very strongly is this } \\
\text { addiction-like desire for food, and } \\
\text { this constant preoccupation with it. } \\
\text { It's more than the physical feeling of } \\
\text { hunger. It also plays on a mental } \\
\text { level.” } \\
\text { Patient with POMC deficiency }\end{array}$ & $\begin{array}{l}\text { “I would eat my way through } \\
\text { everything crosswise, and very } \\
\text { quickly, too. I would always do this in } \\
\text { a certain feeling of stress so that my } \\
\text { parents wouldn't see it, because they } \\
\text { had set up certain rules about food so } \\
\text { that I wouldn't gain weight. So, my } \\
\text { eating was very hectic when I'd eat in } \\
\text { secret.” } \\
\text { Patient with POMC deficiency }\end{array}$ & $\begin{array}{l}\text { "It was not as if I did not try to find } \\
\text { work, but after } 1 \text { or } 2 \text { months } \\
\text { something always occurred, so that I } \\
\text { ended up back in the hospital, or I } \\
\text { had to call in sick and couldn't work. } \\
\text { Of course, I was always fired during } \\
\text { my trial period, and I never arrived at } \\
\text { a long-term employment situation." } \\
\text { Patient with LEPR deficiency }\end{array}$ \\
\hline $\begin{array}{l}\text { “I really had to struggle with myself... } \\
\text { sometimes I could control myself, but } \\
\text { most of the time I couldn't." } \\
\text { Patient with POMC deficiency }\end{array}$ & $\begin{array}{l}\text { “It was like, if there were chips } \\
\text { somewhere, I always kept eating, kept } \\
\text { eating, kept eating, kept eating. Until } \\
\text { someone complained and said I } \\
\text { should stop. Then I had to struggle } \\
\text { with myself, but since everyone was } \\
\text { there and was watching, I somehow } \\
\text { managed it.” }\end{array}$ & $\begin{array}{l}\text { "They took me away when I was } 4 \text { years } \\
\text { old, claiming that my mother was } \\
\text { feeding me to make me fat, and they } \\
\text { took me to some sort of } \\
\text { psychosomatic facility, for over a year, } \\
\text { or a year and a half, where I was } \\
\text { supposed to lose weight. That did not } \\
\text { work either." }\end{array}$ \\
\hline & Patient with POMC deficiency & Patient with LEPR deficiency \\
\hline
\end{tabular}

LEPR leptin receptor, $P O M C$ pro-opiomelanocortin

purposefully overfeeding the patient rather than a condition the patient had.

Four of the five patients reported difficulties with work and/or school. While some issues related specifically to hunger (i.e., attempts to control hunger or obtain food), others pertained directly to being overweight and associated health problems. In describing difficulties at school, one patient with LEPR deficiency mentioned difficulty walking at their heaviest weight and how severe joint pain prevented them from standing or attending recess. This same patient also described how continual hospital visits prevented them from maintaining employment later in life (Table 1).

\section{Changes with Setmelanotide Treatment Noted by Patients}

Reduction and Maintenance of Weight All five patients experienced considerable weight loss following treatment with 
A
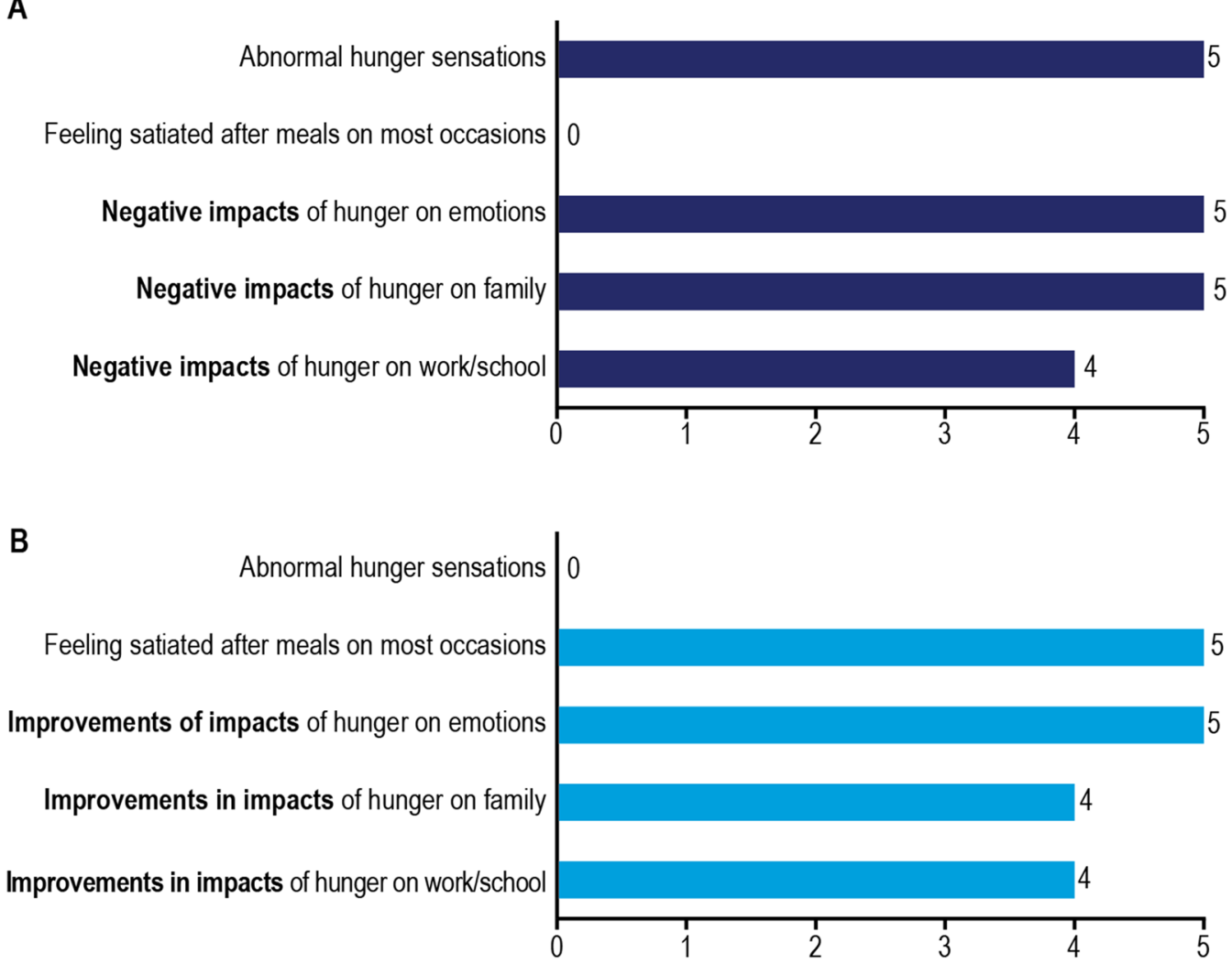

Fig. 1 Number of patients with POMC $(n=3)$ or LEPR $(n=2)$ deficiency who experienced hyperphagia and related impacts on health-related quality of life (a) before

setmelanotide (average, $47.4 \mathrm{~kg}$; range, $25-97 \mathrm{~kg}$ ). Four of the five patients indicated it was very easy to maintain their weight loss with setmelanotide. The remaining patient with LEPR deficiency had initially maintained weight loss, but during the COVID-19 pandemic regained between approximately 10 and $13 \mathrm{~kg}$.

\section{Feelings of Hunger}

All five patients reported notable changes in their hunger following treatment with setmelanotide, including a decrease in the intensity as well as the frequency and duration of their hunger (Table 2). Despite the approximately 3-4 years that elapsed since patients were first treated with setmelanotide, four of five patients said they noticed changes very quickly; the remaining patient with POMC deficiency reported that it took several months and (b) after treatment with setmelanotide. LEPR leptin receptor, $P O M C$ pro-opiomelanocortin

of raising the dose before noticing a reduction in hunger.

Additionally, all five patients reported a decrease in average hunger scores after setmelanotide treatment. Specifically, scores of average hunger ranged from 2 to 7 after treatment, whereas pretreatment average scores ranged from 7 to 9 . Similarly, scores of peak hunger ranged from 5 to 9 after treatment, down from 10 before treatment. While two of five patients had difficulty recalling the exact intensity of their peak pretreatment or posttreatment hunger and did not provide a score, their qualitative descriptions of hunger after treatment were consistent with the decreased numerical rating scale scores of hunger reported. 
Table 2 Patient-reported experiences of hunger, eating habits, and impact of hyperphagia during and after clinical trials with setmelanotide

\begin{tabular}{|c|c|c|}
\hline Feelings of hunger & Eating habits & Impacts of decreased hyperphagia \\
\hline $\begin{array}{l}\text { “A lot has changed, and when I look at } \\
\text { the hunger today, I'm assuming it's } \\
\text { on the same level as other people. I } \\
\text { don't have anything to compare it by, } \\
\text { but I'm just assuming that.” } \\
\text { Patient with POMC deficiency }\end{array}$ & $\begin{array}{l}\text { "I no longer eat as much. For example, } \\
\text { if we make spaghetti Bolognese for } \\
\text { supper in the evening, I'll only eat } \\
\text { one and a half plate [portion], but } \\
\text { usually just one and that will be it." } \\
\text { Patient with POMC deficiency }\end{array}$ & $\begin{array}{l}\text { "Emotionally_it was a burden before } \\
\text { because you were insecure the whole } \\
\text { time because you were always the fat } \\
\text { one, and whenever you had trouble, } \\
\text { you were always afraid, they would } \\
\text { ignore you or insult you. And now } \\
\text { you do not ever have these problems." } \\
\text { Patient with POMC deficiency }\end{array}$ \\
\hline $\begin{array}{l}\text { “Now, I really feel it. My stomach } \\
\text { growls and I notice that I am hungry. } \\
\text { It's a feeling I never had before. It is } \\
\text { funny.” } \\
\text { Patient with LEPR deficiency }\end{array}$ & $\begin{array}{l}\text { “[Now, if }] \text { I am hungry, I eat } \\
\text { something, I am full right away and I } \\
\text { stop, very simple. Previously, I wasn't } \\
\text { able to manage that. It just didn't } \\
\text { work.” } \\
\text { Patient with LEPR deficiency }\end{array}$ & $\begin{array}{l}\text { "Before, I tried for a long time to study, } \\
\text { but I failed due to my physical and } \\
\text { mental state. But now that I've been } \\
\text { receiving the medication, I got into it } \\
\text { very fast, and I'm beginning my final } \\
\text { undergrad[uate] semester, and it's } \\
\text { working really super, I have to say. } \\
\text { There's no comparison. Before, it just } \\
\text { wouldn't have been possible, and now } \\
\text { it's working wonderfully. That's also } \\
\text { a big change." } \\
\text { Patient with POMC deficiency }\end{array}$ \\
\hline $\begin{array}{l}\text { “Now, I do not feel huge hunger, but } \\
\text { sometimes it's difficult to say. It's still } \\
\text { like... You want to eat; you feel the } \\
\text { urge. But the hunger itself is not that } \\
\text { great.” } \\
\text { Patient with POMC deficiency }\end{array}$ & $\begin{array}{l}\text { "I still give thought to food, and maybe } \\
\text { I feel like eating this or that. But I } \\
\text { can choose to eat something, and I } \\
\text { can also set it aside, and in no way } \\
\text { does it still hold this status." } \\
\text { Patient with POMC deficiency }\end{array}$ & $\begin{array}{l}\text { "For me, not being able to work was the } \\
\text { worst thing, to be honest. I simply } \\
\text { could not, and this has changed with } \\
\text { the study and with the weight loss... } \\
\text { I've been working steadily for } 2 \text { years } \\
\text { now, without interruptions and I'm } \\
\text { doing well in my job. It's fun, no } \\
\text { problems at all. It is really } \\
\text { unbelievable." } \\
\text { Patient with LEPR deficiency }\end{array}$ \\
\hline
\end{tabular}

LEPR leptin receptor; POMC pro-opiomelanocortin

\section{Eating Habits}

Consistent with the reductions in their hunger, all five patients reported eating far less than before starting treatment with setmelanotide, both in terms of eating frequency and food quantity (Table 2). All five patients also reported feeling satiated after eating something substantial (e.g., a meal) on most occasions (Fig. 1). Last, all five patients said they are now more likely to desire healthier foods, a meaningful improvement compared with their incessant cravings for sweets and other processed 
Table 3 Patient-reported meaningfulness of improvements in hunger, overall satisfaction of treatment, and feelings if treatment were discontinued

\begin{tabular}{|c|c|c|}
\hline Meaningfulness & Overall satisfaction & Discontinuing setmelanotide \\
\hline $\begin{array}{l}\text { “I'd never have reached the point I'm at } \\
\text { now, and I never would have } \\
\text { experienced and achieved what I've } \\
\text { got. This medication has really } \\
\text { fundamentally transformed my life.” } \\
\text { Patient with POMC deficiency }\end{array}$ & $\begin{array}{l}\text { "I am very satisfied. Really. I am very, } \\
\text { very satisfied. I cannot say any more } \\
\text { about it. It is a blessing that I am } \\
\text { permitted to take this medication.” } \\
\text { Patient with LEPR deficiency }\end{array}$ & $\begin{array}{l}\text { "Oh God. Well, that would be a } \\
\text { catastrophe. I can simply say that. It } \\
\text { would really be a catastrophe. Yes, it } \\
\text { would be the end, somehow." } \\
\text { Mother of patient with LEPR } \\
\text { deficiency }\end{array}$ \\
\hline $\begin{array}{l}\text { “I think it's certainly very important for } \\
\text { my life. That I no longer have the } \\
\text { feeling that I must eat everything, like } \\
\text { an animal. I don't have that anymore. } \\
\text { But the secondary aspects are more } \\
\text { important than the hunger since I've } \\
\text { lost so much weight. My blood values } \\
\text { are good. It's had hugely positive } \\
\text { effects on my life, for which I am very } \\
\text { grateful.” } \\
\text { Patient with POMC deficiency }\end{array}$ & $\begin{array}{l}\text { “It has totally transformed my life. It } \\
\text { was huge, good fortune for me. I } \\
\text { would definitely recommend it to } \\
\text { everybody in my situation, or who } \\
\text { has lived with this illness for a long } \\
\text { time. It causes a great external change } \\
\text { but also a great internal change.” } \\
\text { Patient with POMC deficiency }\end{array}$ & $\begin{array}{l}\text { “I would say I would fall into a very } \\
\text { extreme hole, and I do not know } \\
\text { what would happen. I'm very honest. } \\
\text { I know that the medication has } \\
\text { changed everything for me. I have } \\
\text { already talked to someone about that, } \\
\text { and I said I think I would jump off a } \\
\text { tall building if I no longer had the } \\
\text { medication. I am saying that very } \\
\text { honestly, because if I would imagine } \\
\text { it would be the way it was before, I } \\
\text { would not be able to stand it. I would } \\
\text { not be able to bear it." } \\
\text { Patient with LEPR deficiency }\end{array}$ \\
\hline $\begin{array}{l}\text { “Extremely. I have absolutely no } \\
\text { illnesses at all. I have not been in the } \\
\text { hospital even once, or anything else } \\
\text { like that. I am top fit. I cannot } \\
\text { complain at all. I've got nothing at } \\
\text { all. It's unbelievable... This study } \\
\text { came, and everything changed } \\
\text { immediately. It was absolutely } \\
\text { unbelievable.” }\end{array}$ & $\begin{array}{l}\text { “I'm very satisfied... I've lost a lot of } \\
\text { weight, and I have a lot more energy. } \\
\text { The doctors are very nice, and it's } \\
\text { nice to see that someone is paying } \\
\text { attention to this, and there's a } \\
\text { medication for this, that they're } \\
\text { deploying people to deal with this } \\
\text { problem, when people used to have } \\
\text { to go without care.” }\end{array}$ & $\begin{array}{l}\text { "I have thought about it, and I think } \\
\text { that for me it would mean the end of } \\
\text { the world, because I would probably } \\
\text { gain weight again, and when you gain } \\
\text { weight your life expectancy is not all } \\
\text { that long, since, like I said, I had very } \\
\text { poor blood values. It would be really } \\
\text { terrible." }\end{array}$ \\
\hline Patient with LEPR deficiency & Patient with POMC deficiency & \\
\hline
\end{tabular}

LEPR leptin receptor; POMC pro-opiomelanocortin

carbohydrates before setmelanotide treatment. Patients who still enjoyed their favored pretreatment foods were able to do so in moderation.

\section{Impacts of Reduced Hyperphagia on HRQOL}

All five patients reported considerable improvements in each area of functioning they had previously reported as impaired because of their hunger (Table 2; Fig. 1). With reductions in their hunger and consequently their weight, 
all five patients also reported emotional improvements. In addition to improvements in their mood, patients described feeling more confident and self-assured, as well as feeling relieved that they no longer struggled to control their hunger-related impulses. Additionally, all five patients stated they are more physically active than they were prior to setmelanotide treatment and the subsequent weight loss, commonly noting enjoyment of exercise and/or increased energy.

Reduction of hyperphagia with setmelanotide treatment improved both family dynamics and work/school performance (Table 2 and Fig. 1). As mentioned previously, all five patients reported pretreatment negative impacts of their hunger on family members, mostly stemming from the need for parents to monitor and limit their food intake. While the essential nature of these relationships had not changed, four of five patients reported improvements pertinent to their family members. The remaining patient with LEPR deficiency had been living alone for some time, but described the relationship and interactions with their parents as consistently positive between the time before treatment and the time of the interview.

Two patients described substantial improvements in their ability to work or perform tasks in school following treatment with setmelanotide. One patient with POMC deficiency attributed their success in college to the medication, while the other patient with LEPR deficiency described being able to work a steady job for the first time in their life. Two additional patients described feeling more included and able to do activities similar to their peers at school. The remaining patient with POMC deficiency indicated having some current worklife difficulties; however, these were not attributed to the medication but rather mental fatigue of an unknown origin (Fig. 1).

\section{Perceived Meaningfulness and Overall Patient Satisfaction with Treatment}

All five patients consistently and unequivocally indicated that the improvements in their hunger and subsequent weight loss were very meaningful to them (Table 3). Additionally, all five patients indicated that they were very satisfied with setmelanotide treatment, commonly focusing on their weight loss, as well as the prevention of future weight gain and obesityrelated diseases (Table 3). Not surprisingly, given the positive changes in their lives and level of satisfaction with treatment, all five patients indicated they would be very upset if they had to discontinue treatment with setmelanotide, using words and phrases such as "terrible," "end of the world," "threatening," and "catastrophe." One patient with LEPR deficiency even indicated they would contemplate suicide if denied access to setmelanotide (Table 3).

\section{DISCUSSION}

POMC and LEPR deficiencies are rare genetic diseases characterized by hyperphagia and early-onset obesity that place tremendous burdens on patients and caregivers $[11-13,16]$. The impacts of these burdens on HRQOL are underrecognized and not well characterized [16]. To provide insight into patient experiences of hyperphagia, we conducted in-depth qualitative interviews in a small cohort of patients with obesity due to POMC and LEPR deficiencies participating in an ongoing open-label extension of the phase 3 trials of setmelanotide.

Before treatment with setmelanotide, patients consistently described experiences of extreme hunger, much like an addiction or compulsion to eat. All patients reported impacts of hunger on their daily functioning, including negative emotions, poor self-esteem, and strained interactions with their families. Patients also reported difficulties with work and/or school related specifically to hunger (attempts to control hunger or obtain food), as well as to being overweight and having other health problems.

Following treatment with setmelanotide, most negative impacts attributed by patients to their hunger and/or weight had resolved, and all five patients reported improved mood that had a positive influence on their HRQOL. 
Specifically, patients reported feeling more confident and self-assured and feeling relieved that they no longer struggled with controlling hunger-related impulses. Additionally, all five patients described a quick and profound reduction in their hunger, including a decrease in the intensity and the frequency and duration of hunger. Consistent with these reductions in hunger, all participants reported eating far less food and feeling satiated after eating and experiencing substantial weight loss, which they were able to maintain. Beyond these impacts on daily life, the changes experienced by patients after setmelanotide treatment were personally meaningful, and all five patients indicated that they were very satisfied with setmelanotide treatment.

The qualitative results from these interviews complement the primary results from the phase 3 trials of setmelanotide that used an 11-point scale to determine the hunger score [14]. Following treatment with setmelanotide, the mean peak hunger score decreased from 8.1 (standard deviation [SD], 0.8) at baseline to 5.8 (SD, 2.0) after approximately 1 year on a therapeutic dose in patients with POMC deficiency and from 7.0 (SD, 0.8) at baseline to 4.1 (SD, 2.1) after approximately 1 year on a therapeutic dose in patients with LEPR deficiency [14]. Hunger scores decreased quickly and were maintained throughout the duration of the study during setmelanotide treatment [14].

Of note, there are currently no validated patient- or caregiver-reported assessments of hyperphagia in patients with rare genetic diseases of obesity. The assessments used in the phase 3 clinical trials may be useful in patients with varying degrees of hunger in an untreated state, although it is unclear how meaningful these assessments are for evaluating hyperphagia in patients with POMC and LEPR deficiencies who have never experienced "normal" variations in hunger prior to a treatment baseline reference. However, qualitative data from these interviews provide additional context, given that patients could verbally describe the experiences related to changes in hunger.

\section{CONCLUSION}

Overall, by reducing hunger and improving satiety, treatment with setmelanotide facilitated substantial and meaningful changes in the lives of the patients within our interview cohort. The results of this study confirm that the benefits of treatment with setmelanotide in patients with POMC and LEPR deficiencies surpass favorable clinical changes (e.g., weight and hunger) and are also inclusive of HRQOL improvements that are highly meaningful to patients. Furthermore, to our knowledge, we described the first detailed interviews from the perspective of patients with POMC and LEPR deficiencies that provide valuable insights for clinicians and caretakers.

\section{ACKNOWLEDGEMENTS}

Funding. Open Access funding enabled and organized by Projekt DEAL. This study was supported by Rhythm Pharmaceuticals, Inc. The journal's Rapid Service Fees were also funded by Rhythm Pharmaceuticals, Inc.

Medical Writing and Editorial Assistance. Editorial assistance was provided under the direction of the authors by Katie Veleta, PhD, MedThink SciCom, and funded by Rhythm Pharmaceuticals, Inc.

Authorship. All named authors meet the International Committee of Medical Journal Editors (ICMJE) criteria for authorship for this article, take responsibility for the integrity of the work as a whole, and have given their approval for this version to be published.

Author Contributions. David Richardson, Mark Price, Martin Wabitsch, Peter Kühnen, Sheri Fehnel, and Usha G. Mallya contributed to the study conception. David Richardson, Mark Price, Martina Sluga-O'Callaghan, Martin Wabitsch, Sheri Fehnel, and Usha G. Mallya contributed to study design. David Richardson, Mark Price, Martina Sluga-O'Callaghan, Martin Wabitsch, and Peter Kühnen contributed data acquisition. Data analyses were performed by 
Martina Sluga-O'Callaghan and Sheri Fehnel. Mark Price, Martina Sluga-O'Callaghan, Martin Wabitsch, Peter Kühnen, Sheri Fehnel and Usha G. Mallya contributed to interpretation of the interview data. The first draft was written by Mark Price, Martin Wabitsch, Sheri Fehnel, and Usha G. Mallya. All authors commented on previous versions of the manuscript and approved the final manuscript.

Disclosures. Martin Wabitsch has served as a consultant and speaker for Rhythm Pharmaceuticals, Inc. Sheri Fehnel, Martina SlugaO'Callaghan, David Richardson, and Mark Price are employees of RTI Health Solutions, which was contracted by Rhythm Pharmaceuticals, Inc. to conduct the study. Usha G. Mallya is an employee of Rhythm Pharmaceuticals, Inc. Peter Kühnen has no conflict of interest to disclose.

Compliance with Ethics Guidelines. This study was conducted in accordance with ethical principles founded in the Declaration of Helsinki. The IRB/IEC reviewed and approved all appropriate study documentation. Interview guides were reviewed by MW and PK and approved by the Ethics Commission Berlin (LAGeSo EK Berlin). Informed consent was obtained for participation in the open-label extension study (NCT03651765). Study site staff obtained written informed consent for interview participation and for participant contact information to be provided to RTI Health Solutions for scheduling and conducting interviews. Verbal consent was also obtained prior to recording interviews. All patients provided informed consent for data to be reported in aggregate and anonymously.

Data Availability. Data sharing is not applicable to this article as no datasets were generated or analyzed during the current study.

Open Access. This article is licensed under a Creative Commons Attribution-NonCommercial 4.0 International License, which permits any non-commercial use, sharing, adaptation, distribution and reproduction in any medium or format, as long as you give appropriate credit to the original author(s) and the source, provide a link to the Creative Commons licence, and indicate if changes were made. The images or other third party material in this article are included in the article's Creative Commons licence, unless indicated otherwise in a credit line to the material. If material is not included in the article's Creative Commons licence and your intended use is not permitted by statutory regulation or exceeds the permitted use, you will need to obtain permission directly from the copyright holder. To view a copy of this licence, visit http://creativecommons.org/licenses/by$\mathrm{nc} / 4.0 /$.

\section{REFERENCES}

1. Arnold M, Pandeya N, Byrnes G, et al. Global burden of cancer attributable to high body-mass index in 2012: a population-based study. Lancet Oncol. 2015;16:36-46.

2. Jia H, Lubetkin EI. The impact of obesity on healthrelated quality-of-life in the general adult US population. J Public Health (Oxf). 2005;27:156-64.

3. Centers for Disease Control and Prevention. Childhood obesity causes and consequences. 2021. https://www.cdc.gov/obesity/childhood/causes. html\#: :text=Obesity\%20during\%20childhood\% 20can\%20harm,are\%20more\%20likely\%20to\% 20have\%3A\&text=High\%20blood $\% 20$ pressure $\%$ 20and $\% 20$ high,resistance $\% 2 \mathrm{C} \% 20$ and $\% 20$ type $\%$ 202\%20diabetes. Updated March 19, 2021. Accessed 06 Apr 2021.

4. Ramos Salas X, Forhan M, Caulfield $T$, et al. Addressing internalized weight bias and changing damaged social identities for people living with obesity. Front Psychol. 2019;10:1409.

5. Ford ES, Moriarty DG, Zack MM, et al. Self-reported body mass index and health-related quality of life: findings from the behavioral risk factor surveillance system. Obes Res. 2001;9:21-31.

6. Schwimmer JB, Burwinkle TM, Varni JW. Healthrelated quality of life of severely obese children and adolescents. JAMA. 2003;289:1813-9.

7. Katz DA, McHorney CA, Atkinson RL. Impact of obesity on health-related quality of life in patients with chronic illness. J Gen Intern Med. 2000;15: 789-96. 
8. Nigatu YT, Bültmann U, Reijneveld SA. The prospective association between obesity and major depression in the general population: does single or recurrent episode matter? BMC Public Health. 2015;15:350.

9. Nigatu YT, Reijneveld SA, de Jonge P, et al. The combined effects of obesity, abdominal obesity and major depression/anxiety on health-related quality of life: the LifeLines Cohort Study. PLoS ONE. 2016;11: e0148871.

10. Albuquerque D, Nobrega C, Manco L, Padez C. The contribution of genetics and environment to obesity. Br Med Bull. 2017;123:159-73.

11. da Fonseca ACP, Mastronardi C, Johar A, et al. Genetics of non-syndromic childhood obesity and the use of high-throughput DNA sequencing technologies. J Diabetes Complicat. 2017;31:1549-61.

12. Huvenne H, Dubern B, Clement K, Poitou C. Rare genetic forms of obesity: clinical approach and current treatments in 2016. Obes Facts. 2016;9: 158-73.

13. Heymsfield SB, Avena NM, Baier L, et al. Hyperphagia: current concepts and future directions proceedings of the 2nd International Conference on Hyperphagia. Obesity (Silver Spring). 2014;22(suppl 1):S1-17.

14. Clement K, van den Akker E, Argente J, et al. Efficacy and safety of setmelanotide, an MC4R agonist, in individuals with severe obesity due to LEPR or POMC deficiency: single-arm, open-label, multicentre, phase 3 trials. Lancet Diabetes Endocrinol. 2020;8:960-70.

15. IMCIVREE ${ }^{\mathrm{TM}}$ [package insert]. Boston, MA: Rhythm Pharmaceuticals, Inc.; 2020.

16. Knox J RC, Fay M, McCagg A, et al. Burden of illness associated with rare genetic disorders of obesity. In: Paper presented at: 26th European Congress on Obesity 2019; April 28-May 1, Glasgow, Scotland, 2019. 